\title{
DEVELOPMENT OF BILAYER TABLETS FOR IMMEDIATE AND CONTROLLED RELEASE OF ALLICIN
}

\author{
MANOJ KR. DAS ${ }^{1 *}$, BHANU P. SAHU ${ }^{1}$, JAHAN NUR RAHMAN HAZARIKA ${ }^{1}$ \\ Girijananda Chowdhury Institute of Pharmaceutical Science (GIPS), Hatkhowapara, Azara, Guwahati 781017 Assam \\ Email: mdas5416@gmail.com
}

Received: 15 Feb 2017, Revised and Accepted: 10 May 2017

\begin{abstract}
Objective: The purpose of this study was to develop and evaluate bilayer tablet for the immediate and controlled release of Allicin (Garlic Extract) for effective treatment of Hypertension.

Methods: The immediate release layer was prepared by using super disintegrants-sodium starch glycolate and binder used xantham gum and the sustained release layer was prepared by using hydrophilic polymer like HPMC K 100 and PVP. Before preparation of the tablets, all the preformulation parameters were checked and the tablet of Allicin were prepared by direct compression method and was evaluated for physical characteristics like hardness, weight variation, drug content and friability. In vitro release of drug was performed USP type II dissolution test apparatus using phosphate buffer ( $\mathrm{pH}$ 7.4) as dissolution media and dissolution was continued for 8 hrs for the sustained release layer.
\end{abstract}

Results: It was found that all the formulations were within the limit of the standard. The drug release of the tablet was in the range of $66 \%$ - $83 \%$ in 8 h.

Conclusion: It was concluded that the F4 formulation showed the optimum result as a bilayer tablet for the effective treatment of hypertension.

Keywords: Bi layer tablet, Allicin, Superdisintegrants, Polymer, Direct compression, In vitro dissolution study

(C) 2017 The Authors. Published by Innovare Academic Sciences Pvt Ltd. This is an open access article under the CC BY license (http://creativecommons.org/licenses/by/4.0/) DOI: http://dx.doi.org/10.22159/ijcpr.2017v9i4.20982

\section{INTRODUCTION}

The oral route is the most promising and convenient route of drug administration. Conventional immediate release system achieves as well as maintains the drug concentration within the therapeutically effective range, but one has to take such formulations several times a day [1]. This results in significant fluctuations in plasma drug levels and also the frequency of administration leads to patient noncompliance. Recently, several technical advancements in the pharmaceutical field have led to the development of many novel drug delivery systems that could revolutionise the method of medication and provide a number of therapeutic benefits [2]. Systems can include the maintenance of drug levels within a desired range, the need for fewer administrations, optimal use of the drug in question, and increased patient compliance [3] While these advantages can be significant, the potential disadvantages cannot be ignored like the possible toxicity or non-biocompatibility of the materials used, undesirable by-products of degradation, any surgery required to implant or remove the system, the chance of patient discomfort from the delivery device, and the higher cost of controlled-release systems compared with traditional pharmaceutical formulations [4].

Several pharmaceutical companies are currently developing bi-layer tablets, for a variety of reasons: patent extension, increment in therapeutic efficacy etc. Bi-layer tablet is a new era for the successful development of controlled release formulation along with various features to provide a way of successful drug delivery system and it is suitable for sequential release of two drugs in combination, separate two incompatible substances and also for sustained release tablet in which one layer is immediate release as initial dose and second layer is maintenance dose. ${ }^{5}$ Bi-layer tablets can be primary option to avoid chemical incompatibilities between APIs by physical separation and to enable the development of different drug release profiles. The present article provides a review on the oral drug delivery system, types of tablets, Bilayer tablet manufacturing, various tablet presses used, quality and GMP requirements for high production output and recent developments in the field of Bilayer technology and why development and production of quality bi-layer tablets need to be carried out on purpose built tablet presses, such as layer separation, insufficient hardness, inaccurate individual layer weight control, cross contamination between the layers, reduced yield [6].

Allicin is an organosulphur compound, obtained from garlic. The aroma of garlic when freshly crushed is because of the content allicin released by the action of the enzyme allinase on the substrate alliin [7]. Allicin is an oily based yellowish liquid, which gives garlic its unique colour. Its biological activity can be attributed to both its antioxidant activity and its reaction with thiol containing proteins. The content of garlic by whole weight to its concentration of the bioactive compound is 1:0.001. Allicin has a very short half-life. Alliinase is irreversibly deactivated below $\mathrm{pH} 3$; as such, allicin is generally not produced in the body from the consumption of fresh or powdered garlic [8]. Allicin is unstable, breaking down into inactive components at $230 \mathrm{C}$, thus cooking destroys the bioactive component of garlic. Allicin exhibits lipid lowering, blood thinner, increases local circulation and platelet inhibitor action thus preventing aggregation and clot formation [9].

The aim of the present work is to formulate and evaluate bilayer tablet of Alicin for controlled antihypertensive effect and to achieve immediate release and sustained release of Alicin using bilayered tablet [10].

\section{MATERIALS AND METHODS}

\section{Materials}

Allicin was obtained from Ayurbedic college, Guwahati, assam; Dicalcium Phosphate, Microcrystalline Cellulose, Xanthum gum, Sodium Starch Glycolate, Cross Carmellose Sodium, HPMC K 100, PVP, Magnesium Stearate, Talc were obtained from Merk Specialist pvt. Ltd., Mumbai-18. All other chemicals used were of analytical grade.

\section{Methodology}

Physico chemical parameters

Solubility determination [1]

A minute quantity of the drug sample was taken in a test tube and solubility of the drug dissolving in $1 \mathrm{ml}$ of various solvents 
like water, methanol, ethanol, phosphate buffer etc was observed.

\section{Estimation of allicine in analytical sample}

Preparation of standard calibration curve of Allicin in phosphate buffer pH 7.4 [3]

$100 \mathrm{mg}$ of drug allicin was weighed accurately and dissolved in 100 $\mathrm{ml}$ of phosphate buffer in $100 \mathrm{ml}$ volumetric flask (stock solution). $10 \mathrm{ml}$ was taken from the stock solution and transferred into $100 \mathrm{ml}$ volumetric flask and diluted up to $100 \mathrm{ml}$ with phosphate buffer. From above standard working solution $1 \mathrm{ml}, 2 \mathrm{ml}, 4 \mathrm{ml}, 6 \mathrm{ml}, 8 \mathrm{ml}$, $10 \mathrm{ml}$ up to $20 \mathrm{ml}$ was withdrawn and diluted up to $10 \mathrm{ml}$ Phosphate buffer in $10 \mathrm{ml}$ volumetric flask to get concentration of $20 \mu \mathrm{g} / \mathrm{ml}, 40$ $\mu \mathrm{g} / \mathrm{ml}, 60 \mu \mathrm{g} / \mathrm{ml}, 80 \mu \mathrm{g} / \mathrm{ml}, 100 \mu \mathrm{g} / \mathrm{ml}$ respectively. The absorbance of each solution was measured by UV-visible spectrophotometer at $247 \mathrm{~nm}$ using phosphate buffer as blank.

\section{Formulation of tablet [4]}

The immediate release layer was prepared by using super disintegrants-sodium starch glycolate and xantham gum as a binder and the sustained release layer was prepared by using hydrophilic polymer like HPMC K 100 and PVP. The various ratios of the ingredients used are shown in the formulation table, table 1 before preparation of the tablets all the pre-formulation parameters was checked and the drug and excipients were mixed using suitable blenders to get a premix for direct compression into tablets. And the mixture was then evaluated for various pre-compression parameters such as Bulk Density, Tapped Density, Angle of repose, Hausner's Ratio, Carr's Index.

Table 1: Formulation of bilayer tablets

\begin{tabular}{|c|c|c|c|c|c|c|}
\hline \multicolumn{7}{|c|}{ Immediate release layer } \\
\hline Ingredients & F1 & F2 & F3 & F4 & F5 & F6 \\
\hline Drug (mg) & 20 & 20 & 20 & 20 & 20 & 20 \\
\hline Talk & 2 & 2 & 2 & 2 & 2 & 2 \\
\hline Mg stearate & 2 & 2 & 2 & 2 & 2 & 2 \\
\hline Xantham gum & 5 & 5 & 5 & 5 & 5 & 5 \\
\hline SSG & 12 & 12 & 12 & 12 & 12 & 12 \\
\hline Dicalcium Phosphate & 39 & 39 & 39 & 39 & 39 & 39 \\
\hline MCC & 39 & 39 & 39 & 39 & 39 & 39 \\
\hline \multicolumn{7}{|l|}{ Sustain release layer } \\
\hline Drug & 30 & 30 & 30 & 30 & 30 & 30 \\
\hline PVP & 0 & 0 & 10 & 20 & 6 & 14 \\
\hline HPMC & 10 & 20 & 0 & 0 & 0 & 0 \\
\hline Talk & 4 & 4 & 4 & 4 & 4 & 4 \\
\hline Mg stearate & 4 & 4 & 4 & 4 & 4 & 4 \\
\hline Xantham gum & 20 & 20 & 20 & 20 & 20 & 20 \\
\hline MCC & 132 & 132 & 132 & 132 & 132 & 132 \\
\hline
\end{tabular}

\section{Pre-compression parameters}

\section{Bulk density $\left(D_{b}\right)[5]$}

The accurately weighed powder was carefully transferred into the graduated measuring cylinder. The power bed was then made uniform and the volume occupied by the powder was noted as per the graduation marks on the cylinder as $\mathrm{ml}$. It is expressed in $\mathrm{gm} / \mathrm{ml}$ and is calculated using the following formula.

$$
\mathrm{D}_{\mathrm{b}}=\mathrm{M} / \mathrm{V}_{\mathrm{b}}
$$

Where, M-Mass of the powder

$\mathrm{V}_{\mathrm{b}}$-Bulk volume of the powder

\section{Tapped density $\left(D_{t}\right)[5]$}

It is the ratio of total mass of powder to the tapped volume of powder. The graduated measuring cylinder containing accurately weighed powder was manually tapped for 50 times. Volume occupied by the powder was noted. It is expressed in $\mathrm{gm} / \mathrm{ml}$ and is calculated by following formula.

$$
\mathrm{D}_{\mathrm{t}}=\mathrm{M} / \mathrm{V}_{\mathrm{t}}
$$

Where, M-Mass of the powder

$\mathrm{V}_{\mathrm{t}-\mathrm{T}}$ apped volume of the powder

\section{Angle of repose $(\theta)[5]$}

The frictional forces in a loose powder can be measured by the angle of repose. This is the maximum angle possible between the surface of a pile of powder and the horizontal plane. Sufficient quantities of Allicin powder were passed through a funnel from a particular height $(2 \mathrm{~cm})$ onto a flat surface until it formed a heap, which touched the tip of the funnel. The height and radius of the heap were measured. The angle of repose was calculated using the formula.

Angle of repose $(\theta)=\tan -1(\mathrm{~h} / \mathrm{r})$
Where, h-Height of the pile in $\mathrm{cm}$

r-Radius of the pile.

\section{Compressibility index (I) and Hausner's ratio [5]}

Carr's index and Hausner"s ratio measure the propensity of powder to be compressed and the flowability of granule. Carr"s index and Hausner"s ratio were calculated using following formula.

$$
\mathrm{I}=\mathrm{Dt}-\mathrm{Db} / \mathrm{Dt} \times 100
$$

Where, Dt-Tapped density of the powder

Db-Bulk density of the powder

Hausner"s ratio $=\mathrm{Dt} / \mathrm{Db}=\mathrm{Vb} / \mathrm{Vt}$

\section{Compression of Bilayer tablets [6]}

The bilayer tablets of Allicin were prepared by direct compression method and were evaluated for post compression physical characteristics like hardness, weight variation, drug content and friability. In vitro release of drug was performed USP type II dissolution test apparatus using phosphate buffer (pH 7.4) as dissolution media and dissolution was continued for $8 \mathrm{~h}$ for the sustained release layer.

\section{Post compression parameters}

\section{Tablet dimensions [10]}

Thickness and diameter were measured using calibrated digital Vernier callipers. Five tablets of each formulation were picked randomly and thickness and diameter was measured individually

\section{Hardness test [11]}

The prepared tablets were subjected to hardness test. It was carried out by using Monsanto hardness tester and expressed in $\mathrm{kg} / \mathrm{cm}^{2}$. 


\section{Friability test [11]}

Tablet friability was tested by Roche friabilator. Pre weighed tablets were given 100 revolutions in $4 \mathrm{~min}$ and were dedusted. The percentage weight loss was calculated by reweighing the tablets.

$$
\% F=\frac{[W(\text { initial })-W(\text { final })]}{[W(\text { initial })]} \times 100
$$

\section{Weight variation test [11]}

20 tablets were selected at random from the lot, weighed individually and the average weight was determined. The percent deviation of each tablets weight against the average weight was calculated. The test requirements are met, if not more than two of the individual weights deviate from the average weight by more than $5 \%$ and none deviates more than $10 \%$.

\section{Drug content study [12]}

Three tablets were weight and average weight was determined and powdered. $320 \mathrm{mg}$ of powder was accurately weight and transferred into a $100 \mathrm{ml}$ volumetric flask. It was dissolved and made up the volume with phosphate buffer $\mathrm{pH} 7.4$. After that $1 \mathrm{ml}$ solution diluted in $10 \mathrm{ml}$ phosphate buffer solution. And analyzed at $247 \mathrm{~nm}$ using UV-Visible spectrophotometer. The drug content of each sample was estimated from standard curve of Allicin in phosphate buffer pH7.4.

\section{Drug release study $[12,13]$}

Drug release studies of formulated tablets were conducted in the USP (II) dissolution test apparatus (Lab India, DS8000) using phosphate buffer pH7.4 as dissolution medium maintained at 37. $2{ }^{\circ} \mathrm{C}$. The dissolution vessels were filled with $900 \mathrm{ml}$ of phosphate buffer pH7.4. The vessel maintained at $50 \mathrm{rpm}$ under stirring conditions by means of paddle fabricated for purpose in dissolution apparatus.

The drug dissolution was studied up to $8 \mathrm{~h}$ using $\mathrm{U}$. V spectrophotometry at $247 \mathrm{~nm}$.

\section{Drug release kinetics [13]}

\section{Zero order}

To study the Zero-order release kinetics the release rate data are fitted to the following equation.

$$
F=K \cdot t
$$

Where,

$\mathrm{F}$ is the fraction of drug release,

$\mathrm{K}$ is the release rate constant, and $\mathrm{t}$ is the release time.
When the data is plotted as cumulative percent drug release versus time, if the plot is linear then the data obeys Zero-order release kinetics, with a slope equal to $\mathrm{K}$.

\section{Higuchi's model}

To study the Higuchi kinetics the release rate data are fitted to the following equation-

$$
\mathrm{Q}=\mathrm{K}_{\mathrm{H}} \mathrm{t}^{1 / 2}
$$

Where $Q$ is the amount of drug release at time $t$, and $K_{H}$ is the Higuchi rate constant.

\section{Hixson-Crowell model}

The release rate data were fitted to the following equation-

$$
\text { Q01/3-Qt1/3 = KHC t }
$$

$\mathrm{Qt}$ is the amount of drug released in time $\mathrm{t}, \mathrm{Q} 0$ is the initial amount of the drug in tablet and KHC is the rate constant

\section{Korsemeyer-peppas release model}

$$
\mathrm{M}_{\mathrm{t}} / \mathrm{M}^{\infty}=\mathrm{kt}^{\mathrm{n}}
$$

Where $M_{t}$ is the amount of drug release at time $t$ and $M \infty$ is the amount of drug release after infinite time, $\mathrm{M}_{\mathrm{t}} / \mathrm{M}^{\infty}$ is the factional drug release $\%$ at time $t, K$ is a constant related to the properties of the drug delivery system and $\mathrm{n}$ is the release exponent indicative of the drug release mechanism.

\section{Drug-excipients compatibility study}

\section{FT-Infrared spectroscopy study [13]}

The FTIR analysis was carried out of the pure drug, excipients and the formulation to evaluate the physical stability and compatibility of the drug with the excipients. $10 \mathrm{mg}$ of the sample were taken in a mortar and triturated. A small amount of the triturated sample was taken onto the sample holder and scanned from $400 \mathrm{~cm}^{-1}$ to 4000 $\mathrm{cm}^{-1}$ in FT-IR spectrophotometer (Bruker Alpha-E, modedl no10059736). The spectra obtained were compared and interpreted for the functional group peaks.

\section{Differential scanning calorimetry study [13]}

A Differential scanning calorimeter (Perkin Elmer (USA), Model-jade DSC) was used for determining the compatibility of drug and the excipients. Individual sample of pure drug, excipients and the formulation were weighed to about $5 \mathrm{mg}$ in the DSC aluminum pan and scanned in the temperature range of $50-300{ }^{\circ} \mathrm{C}$ in nitrogen environment. A heating rate of $10{ }^{\circ} \mathrm{C}$ per minute was used, and the thermo gram were reviewed for evidence of any interaction.

\begin{tabular}{|c|c|c|c|c|c|}
\hline Formulation code & Bulk density gm/ml & Tapped density gm/ml & Carr's index (\%) & Hausner's ratio & Angle of repose $(\theta)$ \\
\hline F1 & 0.552 & 0.503 & 7.32 & 1.1 & 25.5 \\
\hline $\mathrm{F} 2$ & 0.573 & 0.513 & 6.45 & 1.17 & 23.33 \\
\hline F3 & 0.535 & 0.495 & 9.52 & 1.15 & 27.34 \\
\hline F4 & 0.582 & 0.552 & 7.57 & 1.19 & 25.32 \\
\hline F5 & 0.522 & 0.531 & 8.51 & 1.14 & 24.42 \\
\hline F6 & 0.594 & 0.556 & 9.53 & 1.15 & 25.57 \\
\hline
\end{tabular}

\section{RESULTS AND DISCUSSION}

Table 2: Pre formulation studies of the drug

\begin{tabular}{lll}
\hline S. No. & Parameters & Result \\
\hline 1 & Organoleptic Properties & Crystalline powder \\
& Bulk Characteristic & Light Brownish red \\
& Color & Characteristic \\
& Odor & Partially insoluble in water \\
& Solubility & Freely soluble in methanol \\
& & Soluble in alcohol \\
3 & Absorption spectra & $247 \mathrm{~nm}$ \\
\hline
\end{tabular}

Table 3: Pre-formulation studies of the powder 

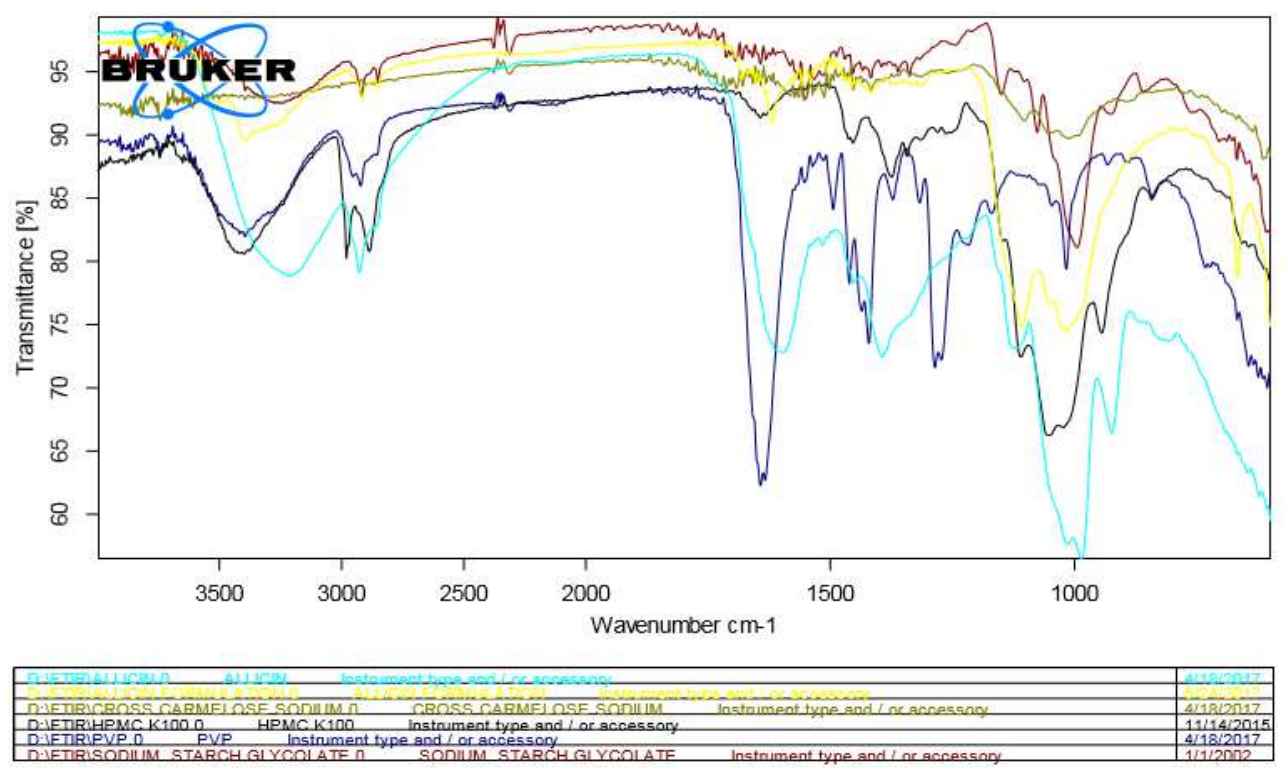

Fig. 1: FTIR of drug and excipients

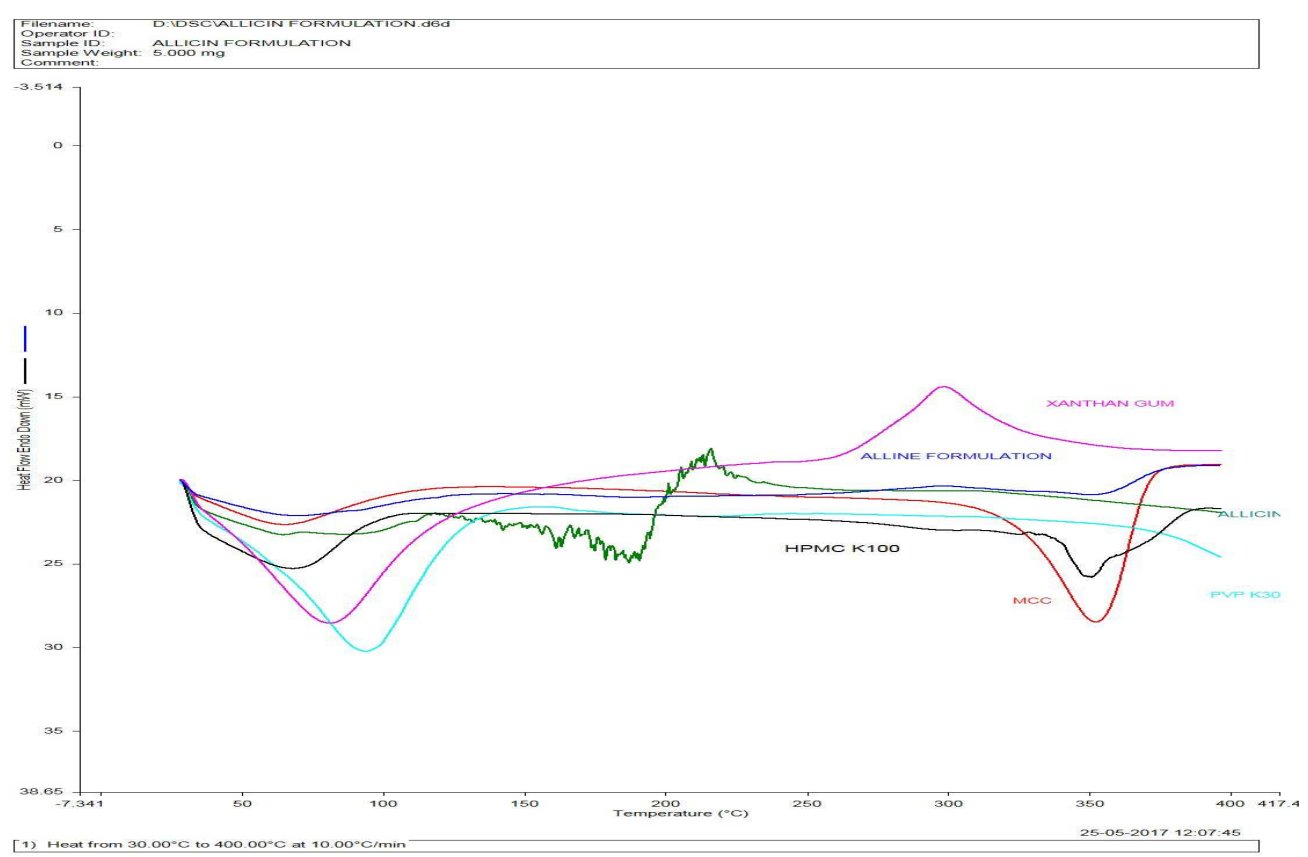

Fig. 2: DSC thermogram of drug, excipients and formulation. (SSG-sodium starch glycolate, CCS, MCC-micro crystalline cellulose)

Table 4: Post compression parameters

\begin{tabular}{lllll}
\hline Batch code & Wt. variation $\%$ & Hardness $\left.\mathbf{( k g} / \mathbf{c m}^{\mathbf{2}}\right)$ & Thickness $(\mathbf{m m})$ & Drug content \% \\
\hline F1 & $318 \pm 2.20$ & 3.6 & 4 & 97.45 \\
F2 & $315 \pm 3.1$ & 3.8 & 4 & 102.91 \\
F3 & $321 \pm 1.2$ & 4.2 & 3.8 & 93.23 \\
F4 & $318 \pm 2.2$ & 4.3 & 4.1 & 96.37 \\
F5 & $316 \pm 2.8$ & 3.8 & 4.1 & 95.37 \\
F5 & $321 \pm 1.2$ & 4.5 & 3.8 & 98.41 \\
\hline
\end{tabular}




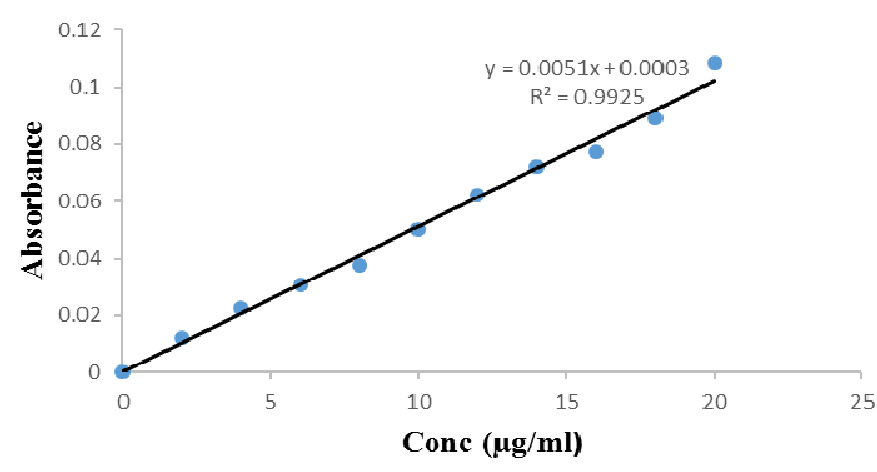

Fig. 3: Calibration curve of allicine in phosphate buffer $\mathrm{pH} 7.4$

Table 5: Dissolution results

\begin{tabular}{|c|c|c|c|c|c|c|}
\hline Time & F1 & F2 & F3 & F4 & F5 & F6 \\
\hline 0 & 0 & 0 & 0 & 0 & 0 & 0 \\
\hline 10 & 23.705882 & 14.647059 & 18.176471 & 11.117647 & 21.705882 & 20.364706 \\
\hline 20 & 26.247059 & 17.188235 & 24.247059 & 17.258824 & 24.247059 & 22.411765 \\
\hline 30 & 29.776471 & 20.717647 & 27.776471 & 25.835294 & 27.776471 & 23.541176 \\
\hline 40 & 32.6 & 23.541176 & 28.129412 & 31.552941 & 30.6 & 25.588235 \\
\hline 50 & 33.188235 & 42.247059 & 31.658824 & 32.752941 & 35.188235 & 30.776471 \\
\hline 60 & 35.011765 & 46.129412 & 41.188235 & 39.423529 & 38.011765 & 38.717647 \\
\hline 120 & 41.952941 & 48.952941 & 52.482353 & 40.058824 & 48.952941 & 44.011765 \\
\hline 180 & 46.247059 & 53.541176 & 53.541176 & 40.376471 & 54.247059 & 48.247059 \\
\hline 240 & 53.717647 & 68.717647 & 59.541176 & 40.764706 & 62.717647 & 52.129412 \\
\hline 300 & 66.011765 & 70.482353 & 65.541176 & 44.294118 & 74.011765 & 57.070588 \\
\hline 360 & 74.364706 & 76.835294 & 70.129412 & 48.141176 & 80.364706 & 62.717647 \\
\hline 420 & 79.835294 & 80.364706 & 74.011765 & 61.094118 & 82.835294 & 68.717647 \\
\hline 480 & 82.717647 & 83.541176 & 80.364706 & 66.035294 & 86.717647 & 76.835294 \\
\hline
\end{tabular}

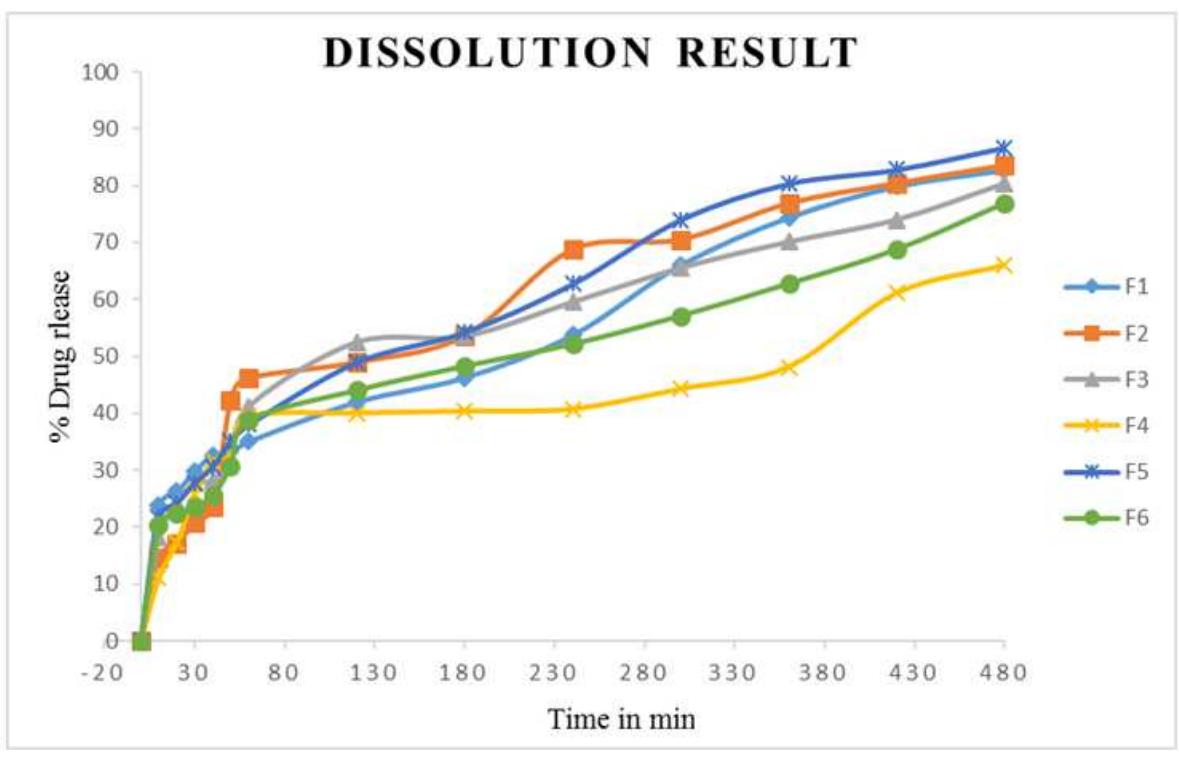

Fig. 4: Dissolution curve

Table 6: Release kinetics parameters

\begin{tabular}{|c|c|c|c|c|c|}
\hline Formulation & $\begin{array}{l}\text { Zero order } \\
\mathbf{R}^{2}\end{array}$ & $\begin{array}{l}\text { First Order } \\
\mathbf{R}^{2}\end{array}$ & $\begin{array}{l}\text { Higuchi } \\
\mathrm{R}^{2}\end{array}$ & $\begin{array}{l}\text { Hixon crowell } \\
\mathbf{R}^{2}\end{array}$ & Korsemeyer-peppas (n) \\
\hline F1 & 0.5101 & 0.7678 & 0.9451 & 0.7053 & 0.394 \\
\hline F2 & 0.5506 & 0.8684 & 0.9497 & 0.7991 & 0.420 \\
\hline F3 & 0.3966 & 0.7633 & 0.9395 & 0.6685 & 0.370 \\
\hline F4 & 0.1246 & 0.3822 & 0.7916 & 0.3007 & 0.313 \\
\hline F5 & 0.5419 & 0.8589 & 0.9719 & 0.7930 & 0.404 \\
\hline F6 & 0.4118 & 0.6987 & 0.9395 & 0.6187 & 0.371 \\
\hline
\end{tabular}




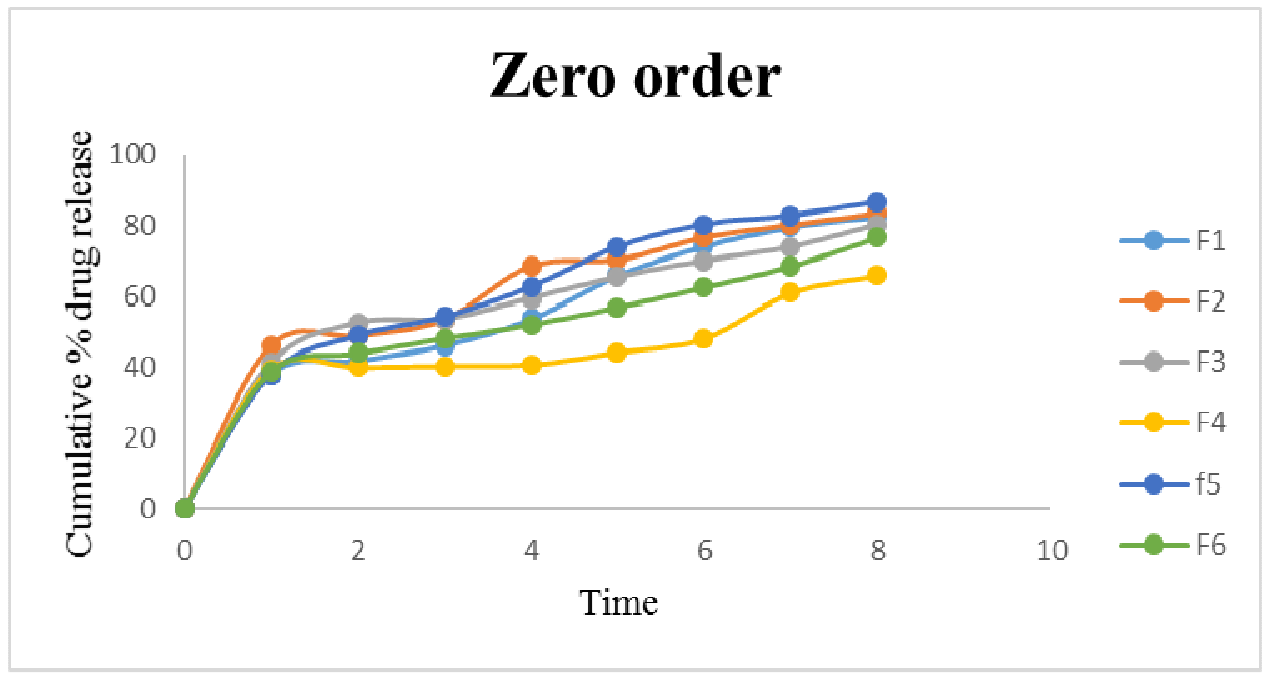

Fig. 5: Plot showing zero order kinetics of 6 formulation

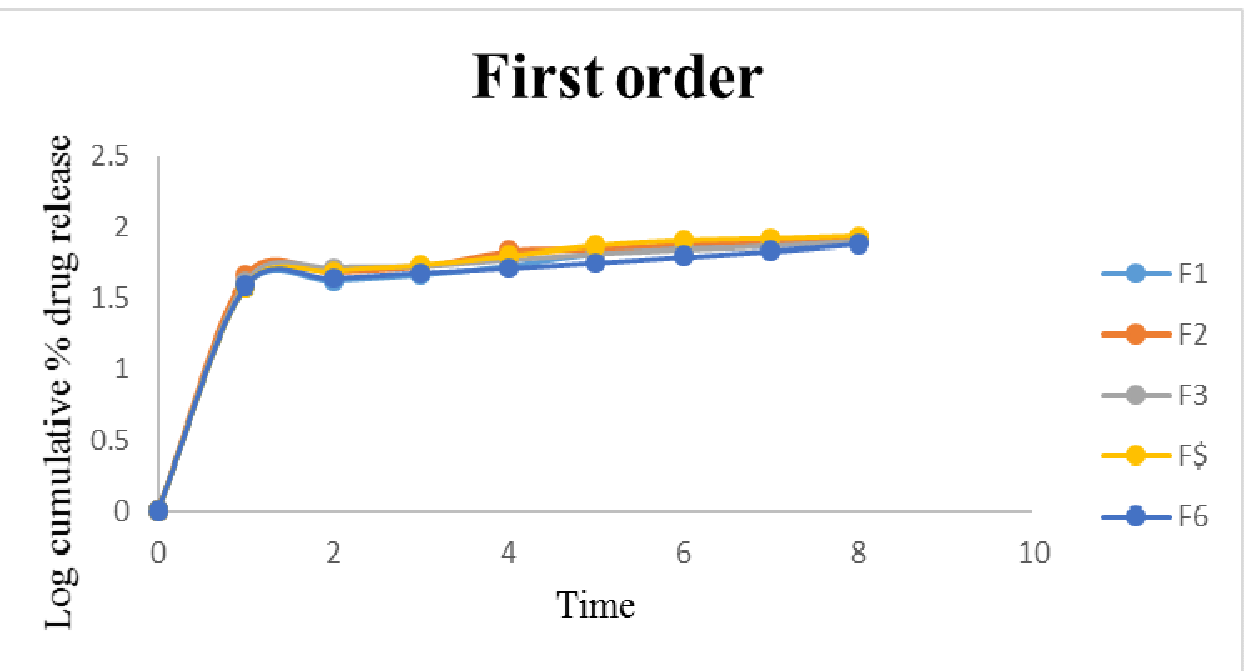

Fig. 6: Plot showing first order kinetics of 6 formulation

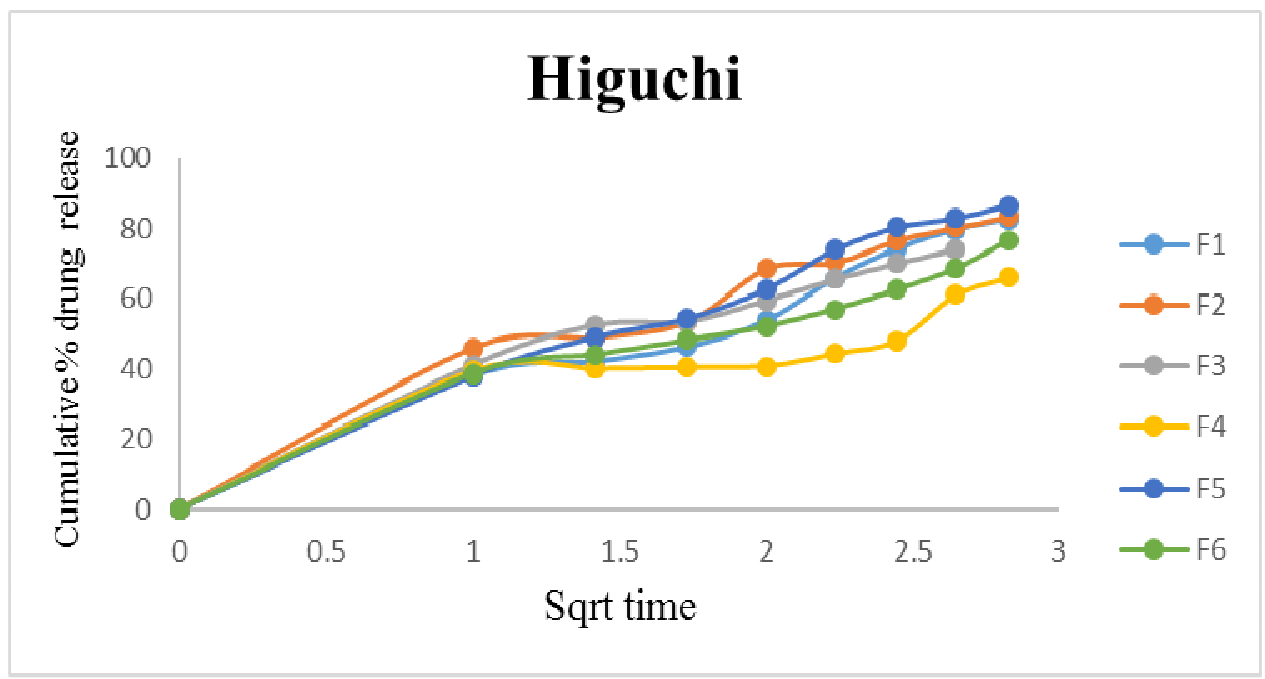

Fig. 6: Plot showing higuchi model of 6 formulation 


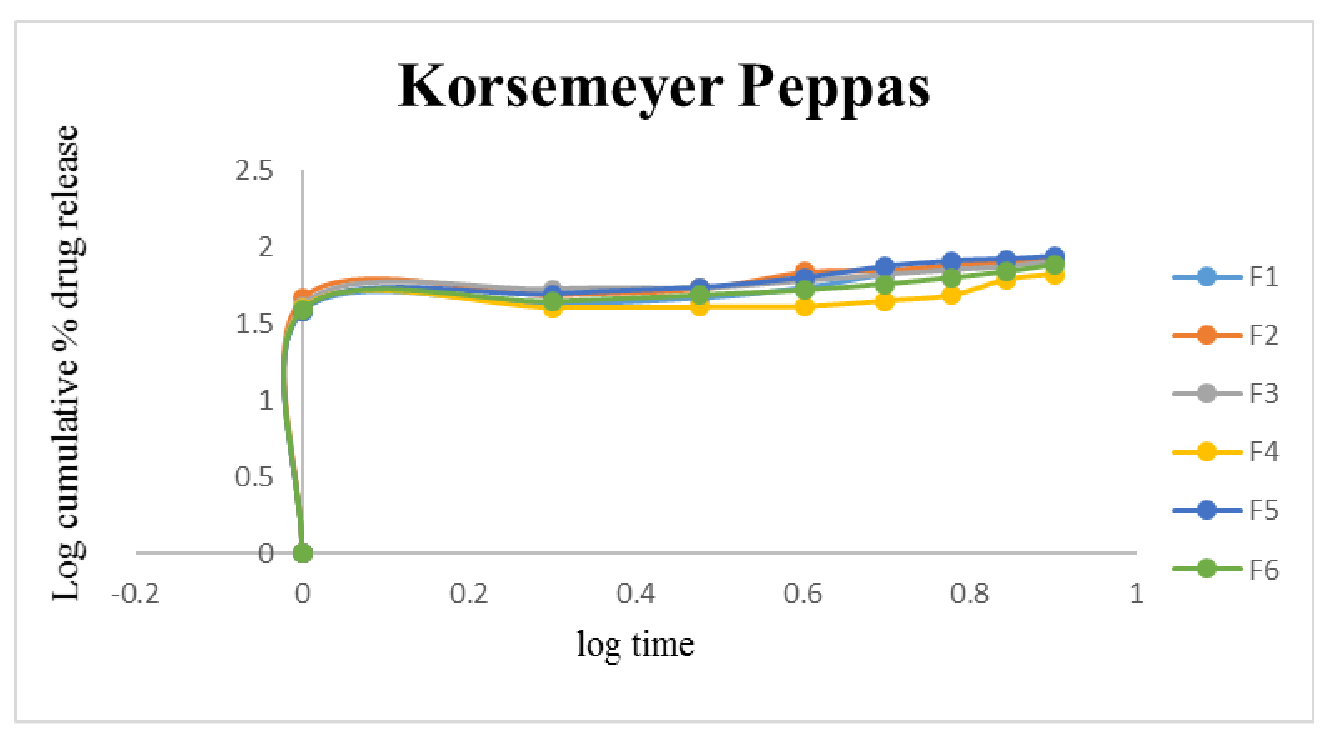

Fig. 7: Plot showing korsemeyer pappas model of 6 formulation

\section{RESULTS AND DISCUSSION}

The drug is soluble in Alcohol, partially soluble in water, freely soluble in methanol and phosphate buffer. The characteristic of the drug is polar. The bulk characteristic of the drug is crystalline, color obtain light brownish red and odor characteristic. The prepared Allicin powders for tableting were prepared by the suitable blender. The prepared powder were evaluated for angle of repose, bulk density, tapped density and compressibility index, Hausner's ratio. The bulk densities and tapped densities of the powder were found to be in the range of 0.522 to $0.594 \mathrm{gm} / \mathrm{ml}$ and 0.495 to $0.503 \mathrm{gm} / \mathrm{ml}$. The angle of repose varied from 23.33 to 25.57 which indicate good flow properties of the powder. Hausner's ratio was ranged between 1.1 to 1.19 , while the compressibility index was in the range of 6.24 to 9.53 these values indicates that the powder mixture of all batches of formulation exhibited good flow properties.

The prepared tablets were evaluated for Weight variation, Hardness, Friability, Thickness, drug content. Thickness was found to be in the range of 3.8 to $4.1 \mathrm{~mm}$ and the hardness of the tablets was in the range of 3.6 to $4.8 \mathrm{~kg} / \mathrm{cm} 2$ which was sufficient for the handling of tablets throughout the shelf life. \% friability was between $0.67-0.96$ $\%$ which is within the acceptable limit. From the weight variation test the \% weight variation for all 20 tablets were found $321 \pm 1.2$ $315 \pm 3.1$ in and the drug content was found to satisfactory in the range of $93.23-102.91 \%$. Drug and excipient are accurately weight and compress by direct compression method using $6 \mathrm{~mm}$ dye. Six formulation are done properly. The in vitro dissolution studies were carried out for all the 6 formulation in USP apparatus type II using dissolution medium of phosphate buffer $\mathrm{pH}$ 7.4. The percentage release of Alicin tablet are plotted. Above this 6 formulation, the formulation $\mathrm{F} 4$ with the concentration of polymer PVP $20 \mathrm{mg}$ showed better drug release by releasing $66 \%$ at the end of $8 \mathrm{~h}$. From the kinetic study the drug release from drug layer follows Higuchi equation. And from the Korsemeyer-Peppas model the " $n$ " values of the prepared formulation were found to be between 0.313 to 0.4109 $(<0.5)$ indicating diffusion controlled release of drug.

The FT-IR was performed for drug, excipients and tablet Formulation. From the FT-IR study it is clearly understood the identical FT-IR bands were also present in the drug excipients physical mixture as like that of the drug. This confirms that there are no drug excipient interactions present. DSC studies of the pure drug and excipient were carried out to determine if there was any interaction between the drug and the excipient. The spectra showed peak at $156.14{ }^{\circ} \mathrm{C}$ for the drug itself and at $71.70{ }^{\circ} \mathrm{C}$ for the mixture which corresponds to its melting point. Thus, the thermal data did not reveal any interaction between the drug and the excipients used for the prototype formulation development.

\section{CONCLUSION}

The present work involves the bi layer tablets for the immediate and controlled release of Allicin using HPMC K100 and PVP as a retardant polymer. The drug-excipient compatibility studies confirmed that the both drugs are compatible with selected polymer HPMC K100 and PVP. The pre-compression parameters and post compression parameters were obtained from both the layers and were within the acceptable limits. The drug release study from Allicin sustains release layer showed that as the concentration of the polymer increase the drug release is decreases. The release of drug in the first hour varies between 35.01 to 46.12 and the second layer duration of drug release varies 66.03 to 86.71 . The results reveal that with increase concentration of HPMC K100 and PVP retardation of drug release takes place. From the kinetic study the drug release from drug layer follows Higuchi equation and Korsemeyer-Peppas indication drug release. The " $n$ " values of the prepared formulation were found to be between 0.313 to 0.4109 indicating diffusion controlled release of drug. The drug release study tablet showed desired release profile for both layer. The complete drug release is taken eight hours. Hence the formulated bi layer tablet can be used for effective and prolonged management of Blood pressure and it use for the treatment of Hypertension.

\section{CONFLICT OF INTERESTS}

Declare none

\section{REFERENCES}

1. Ghugarkar P, Swain K, Suggala V, Adsare P, Shaik P. Review on bilayer tablet technology. World J Pharm Res 2009;4:1434-52.

2. Motarwar SS, Jadhav SB, Kadam VS, Muttepawar SS, Bharkad VB, Zamiruddin M. Review on-bilayer tablet. World J Pharm Pharm Sci 2013;3:2693-709.

3. Barthwal P, Ganarajan P, Kothiyal P. Review on bilayer tablet. Int J Pharm Chem Sci 2013;2:1788-97.

4. Neeraj B, Kumar A, Choudhary A, Choudhary R, Bala R. A review on immediate release drug delivery system. Int Res J Pharm Appl Sci 2014;4:78-87.

5. Bhowmik D, Gopinath H, Kumar BP, Duraivel S, Kumar KPS. Controlled release drug delivery systems. Pharma Innovation 2012;1:24-32.

6. Patel M, Ganesh, Nanjan S. Challenges in the formulation of bilayer tablets; a review. Int J Pharma Res Dev 2010;4:974-9446.

7. Panchal HA, Tiwari AKA. Novel approach of bi-layer tablet technology a review. Int Res J Pharm 2012;3:44-9.

8. Deshpande RD, Gowd DV, Nawaz M, Maramwar DN. Bi-layer tablets an emerging trend a review. Int Res J Pharm 2011;2:2534-44. 
9. Singh KP, Kumar S, Bilayer and floating bioadhesive tablets: innovative approach to gastroretention. J Drug Delivery Ther 2011;1:32-5

10. Gopinath C, Hima Bindu V, Nischala M. An overview on bilayer tablet technology. J Global Trends Pharm Sci 2013;4:1077-85.

11. Madhura TK. Miracle of allicin, a case report. Int J Sci Res 2015;5:1-3.

12. Katare C, Shrivastava Y, Saxena S. Neutraceutical potential of organosulfur compounds in fresh garlic and garlic preparations. Int J Pharma Bio Sci 2014;5:112-26.
13. Rashmin N, Praful D. Formulation and evaluation of dual component tablets of metoprolol tartrate. Int J Pharm Chem Sci 2012;1:514-22.

\section{How to cite this article}

- $\quad$ D Radhika, A Mohaideen. Manoj KR Das, Bhanu P Sahu, Jahan Nur Rahman Hazarika. Development of bi layer tablets for immediate and controlled release of allicin. Int J Curr Pharm Res 2017;9(4):153-160. 